\title{
A projeção da cidade nas efemérides jornalísticas: estudo do suplemento Cultura de Zero Hora (2006-2009) ${ }^{1}$
}

\section{Cida Golin}

Doutora; Universidade Federal do Rio Grande do Sul golin.costa@ufrgs.br

\section{Anna Cavalcanti}

Mestranda; Universidade Federal do Rio Grande do Sul annaccavalcanti@gmail.com

\section{Julia Correa da Rocha}

Bacharel; Universidade Federal do Rio Grande do Sul juliacorreadarocha@gmail.com

\section{Resumo}

As efemérides sinalizam o poder do campo jornalístico de construção da memória social, de participar das disputas que definem aquilo que deve ser lembrado e os modos de acionar esta lembrança. Nas rotinas planejadas do jornalismo cultural, são recursos para atualizar e reinserir temas, personagens e produtos na economia da oferta de bens culturais. Este artigo discute como o suplemento Cultura de Zero Hora, entre 2006 e 2009, recorreu às efemérides e de que forma a escolha de boa parte dos eventos cíclicos configurou-se como narrativa daquilo que deve ser lembrado sobre a cidade. Retomam-se índices obtidos na análise de conteúdo de 1.413 textos em 208 edições do caderno Cultura de ZH no período. Desse total, analisa-se um conjunto de temas de capa selecionados para discussão. A presentificação do passado aponta para três movimentos de projeção da cidade: a espacialidade personalizada, a espacialidade material e a espacialidade imaterial.

\section{Palavras-chave}

Efemérides. Suplemento cultural. Caderno Cultura (ZH). Cidade.

\section{Introdução}

Procedimento típico nas rotinas planejadas do jornalismo cultural, as comemorações e as efemérides são recursos para atualizar a memória em torno de determinados temas, rein-

\footnotetext{
${ }^{1}$ Versão expandida e revisada de paper homônimo submetido para apresentação no 13 o Encontro Nacional de Pesquisadores em Jornalismo - SBPJOr 2015
} 
serir pautas, personagens e produtos na economia da oferta dos bens culturais. Por meio do gancho jornalístico marcador de um movimento cíclico, como as estações do ano, os aniversários de nascimento e morte (efemérides pessoais) e as celebrações de datas, estes eventos tornam-se rituais de interpretação do passado. Neste artigo, buscamos refletir sobre como o suplemento semanal Cultura de Zero Hora (ZH), entre 2006 e 2009, recorreu às efemérides, dando poder de contemporaneidade ao passado (JEUDY, 2005), e de que forma a escolha de boa parte dos eventos cíclicos configurou-se como narrativa daquilo que deve ser lembrado sobre a cidade.

Esta reflexão apresenta resultados parciais da investigação Jornalismo e sistema cultural: estudo da cidade no suplemento Cultura de Zero Hora (2006-2009), com financiamento do Conselho Nacional de Desenvolvimento Científico e Tecnológico (CNPq) 2 . Em âmbito geral, a pesquisa busca problematizar a construção jornalística da cidade como espaço de capital simbólico e criativo. É importante situar que o caderno Cultura foi não apenas o primeiro, em abril de 1967, a consolidar o formato do suplemento semanal na imprensa do Rio Grande do Sul, como se constituiu em um dos suplementos culturais mais longevos do Brasil. Somente na sua periodicidade semanal, ${ }^{3}$ foram 22 anos de circulação ininterrupta entre 1992 e 2014, período em que foi o único espaço da imprensa diária do estado ${ }^{4}$ a aglutinar intelectuais e acadêmicos, mediando saberes especializados para um público mais amplo. Em maio de 2014, foi substituído pelo caderno dominical PrOA, no âmbito das reformulações editoriais que o jornal Zero Hora promoveu na passagem de seu cinquentenário.

Estudos realizados (GOLIN et al., 2014) apontaram que o suplemento aqui estudado rege-se, especialmente, pelo valor da notoriedade e, apesar do leque eclético e abrangente de temáticas, tem no mercado editorial um dos eixos fundamentais de produção de pautas. A narrativa em fragmentos sobre a cultura, proposta pela publicação, estrutura-se no acontecimento repetitivo e pré-agendado da maioria das pautas (eventos) e pela presença privilegiada da efeméride. 0 caderno organiza-se a partir de um tempo previsível e provocado pelo gesto de interpretação editorial, gesto este tensionado pela exigência de ordenar a apreen-

\footnotetext{
${ }^{2}$ A investigação está inserida nas atividades do Núcleo de Estudos em Jornalismo e Publicações Culturais do Laboratório de Edição, Cultura \& Design (LEAD), grupo registrado no CNPq, situado na Faculdade de Biblioteconomia e Comunicação da Universidade Federal do Rio Grande do Sul (FABICO|UFRGS) e vinculado à linha Jornalismo e Processos Editoriais do Programa de Pós-graduação em Comunicação e Informação (PPGCOM|UFRGS).

${ }^{3}$ Desde sua primeira versão em 1967, o caderno alternou periodicidades quinzenais e mensais e teve uma interrupção de 11 anos (1970-1981).

${ }^{4}$ Dados do Instituto Verificador de Circulação (IVC) apontam que ZH era o jornal com maior circulação do Sul do Brasil em 2014 , com alcance semanal de mais de 740 mil leitores em Porto Alegre e Grande Porto Alegre e mais de 175 mil exemplares/dia (MENDES, 2014). Dados do IVC, disponíveis no site da Associação Nacional de Jornais, colocam Zero Hora como o sexto maior jornal do Brasil em circulação paga. Disponível em: <http://www.anj.org.br/maiores-jornais-do-brasil/\#>. Acesso em: 27 jul. 2015.
} 
são do presente e iluminar um passado que fundamenta boa parte do seu conteúdo editorial. A efeméride sinaliza o poder do campo jornalístico de construção da memória social, de participar das disputas que definem aquilo que deve ser lembrado e os modos de acionar esta lembrança, seja pela homenagem, pelos discursos laudatórios e hiperbólicos ou por outras estratégias discursivas.

Neste exercício analítico, dialogamos com diversos autores em torno da cidade como tecido narrativo e, também, sobre o jornal enquanto lugar de agenciamento da memória, espaço mobilizador de sentidos sobre a urbe. A seguir, retomaremos índices obtidos na leitura dos resultados quantitativos da análise de conteúdo de 1.413 textos em 208 edições do caderno, entre 2006 e 2009, e refletiremos sobre um conjunto de temas de capa selecionado especialmente para esta discussão.

\title{
2 Narrativas circulares da lembrança: efeméride jornalística e o texto da cidade
}

O jornalismo é uma instituição ancorada na produção da vivência social do momento presente (FRANCISCATO, 2005). Um jornal abre portas para múltiplas temporalidades, sempre ordenadas por sua narratividade. Do ponto de vista da percepção social, ele pode condensar e ampliar fronteiras daquilo que se entende por passado, presente e futuro (MATHEUS, 2011). Nesse processo, a comemoração ritualística é um gesto interpretativo no âmbito da função temporalizante da instituição jornalística. Trata-se de uma espécie de "agendamento da lembrança”, segundo Dias (2014, p. 212-213), em que “[...] a imprensa trabalha seletivamente com aquilo que pretende fazer ser visto, reconhecido e lembrado [...]". Se uma história deve ser lembrada, outras tantas serão silenciadas.

Entre os lugares simbólicos da memória descritos por Pierre Nora (1993), podemos localizar os aniversários, as comemorações, as festas e as peregrinações, como sacralizações passageiras de uma sociedade que dessacraliza.

\begin{abstract}
Os lugares de memória nascem e vivem do sentimento que não há memória espontânea, que é preciso criar arquivos, que é preciso manter aniversários, organizar celebrações, pronunciar elogios fúnebres, notariar atas, porque essas operações não são naturais (NORA, 1993, p. 13).
\end{abstract}

Diante de nossa capacidade de registro desses lugares simbólicos, uma questão vem à tona: registramos a memória para poder lembrar ou esquecer? Como explica Gagnebin (2009; 2014), o surgimento desse paradoxo remete à origem da própria escrita enquanto 
uma das mais antigas formas de tentar transformar em signos a forma abstrata da lembrança: o termo sèma, da qual deriva a palavra "signo", também significa, em sua origem, túmulo. Não é por acaso que as inscrições funerárias estejam entre os primeiros rastros de signos escritos. Gagnebin $(2009 ; 2014)$ esclarece que o trabalho de pesquisa e de criação de significação também é, ao mesmo tempo, um trabalho de luto. Registramos, na verdade, para poder enterrar o passado; mas, ao mesmo tempo, o túmulo é um memorial que lembra as façanhas do morto, que registra a sua existência para que ele não seja esquecido.

O registro de discursos comemorativos e celebratórios - operados pelo trabalho de enquadramento da memória (POLLAK, 1989) e que tem na instituição jornalística um de seus artífices - constitui balizas importantes para pensar a construção do discurso da e sobre a urbe. Nesse sentido, partilhamos da perspectiva da cidade como texto (CERTEAU, 2012) sempre em reescrita, tecido narrativo vivido no presente, que nunca para de inventar-se e de brincar com sua história: "Há memória, mas esta não tem outro sentido senão o de reavivar o espírito da fundação, de reatar os fios de uma história que não é unilateral, mas um enovelado de narrações." (MONGIN, 2009, p. 57). A cidade é construída discursivamente e, nesse processo, entram em disputa distintos relatos e perspectivas.

Estamos considerando lugar como uma espacialidade real ou imaginária. A cidade, segundo Limonad e Randolph (2002), seria um lugar socialmente criado em determinado contexto histórico-espacial. Com Halbwachs (2006), entendemos que uma das funções da memória é criar o sentimento de pertencimento. Os laços entre lugares e pessoas constroem tanto a identidade coletiva como também define o sentido do lugar.

Se um dos percursos mais frequentes pelas cidades contemporâneas obedece cada vez mais o ritmo dos museus e dos guias turísticos (MONGIN, 2009, p. 53), o jornalismo cultural configura-se como lócus expressivo para perscrutar a cidade atravessada pela "inovação", pelas "conexões" e pela "cultura". Em geral, a cobertura especializada potencializa tal discurso e, ao seguir a lógica de oferta da economia da cultura, funciona como guia de orientação para o consumo, investindo, pela constante reiteração, em determinados espaços simbólicos e percepções sobre a urbe. A partir de Harvey (2005), é possível situar o jornalismo junto aos guardiões do capital cultural e simbólico coletivo, instâncias estas articuladas pela ação dos museus, universidades, mecenas, aparelho estatal, entre outros. ${ }^{5}$

${ }^{5}$ A partir de uma perspectiva crítica da construção dos discursos de "singularidade" e "autenticidade" que norteiam as narrativas dos
ambientes sociais e culturais, especialmente das cidades contemporâneas que ambicionam a distinção, Harvey (2005. p. 230-232)
indaga qual memória coletiva deveria ser celebrada pela cidade. Nessa reflexão, Harvey refere-se à ascensão de Barcelona à proemi- 
Encontramos no jornalismo, portanto, um lugar de memória da cidade. A partir de seu lócus de visibilidade, especifica critérios para interpretar a memória e a cultura da urbe, define o que deve ser lembrado e aquilo que é ou não especial.

\section{Hierarquia da memória: a efeméride a partir da panorâmica editorial do suplemento Cultura}

A cobertura jornalística oferece instantâneos concentrados sobre o sistema cultural, apresenta recortes sobre os diversos segmentos e agentes em disputa, estabelece hierarquias e valoração estética ao destacar determinados eventos ou silenciar outros. 0 suplemento semanal, por sua vez, constitui um reduto ainda mais hierarquizado, considerando que ali estaria o que de mais significativo se discute e se produz, para além do registro de agenda e serviço que conforma a maior parte da cobertura diária. Pela sua periodicidade mais alargada, abriga temporalidades heterogêneas e carrega consigo parte do conceito etimológico da revista, ou seja, o ato da re-vista, de examinar, de inspecionar mais detidamente, pressupondo o exercício da crítica e do ensaio. Seguindo a tradição das revistas literárias, articulase sobre uma montagem de fragmentos heterogêneos (materiais jornalísticos, textos analíticos e excertos ficcionais, eventualmente), cujas relações não são necessariamente lineares, mas aleatórias ou mesmo anacrônicas (ANTELO, 1997; VOGEL, 2011).

Esse possível anacronismo, muito presente no segmento cultural mais especificamente, revela a capacidade de acionar a presentificação do passado por meio de uma mediação temporal mais alargada, que faz referência a temas, pessoas ou obras que não necessariamente fazem parte da agenda do momento. Dessa maneira, para que se faça um resgate histórico, e o assunto seja contemplado em toda a sua dimensão, são necessários textos mais aprofundados e que, muitas vezes, exigem um repertório intelectual prévio do leitor. Essa característica é relevante especialmente quando traçamos um paralelo com o jornalismo factual, que, em geral, prioriza o presente e a imediatez. Pensando nessa temporalidade heterogênea, entendemos que a efeméride é um valor-notícia essencial ao jornalismo cultural por fazer recircular temas que, frente à lógica do presentismo (HARTOG, 2005) contemporâneo, talvez não viessem à tona em editorias que dispõem de um tempo mais curto para a construção da pauta. No objeto que escolhemos para análise, conforme observamos a seguir, percebemos a expressividade desse valor-notícia.

nência do sistema europeu de cidades, acumulando capital simbólico e marcos de distinção com poder de atração importante em relação aos fluxos de capital (2005, p. 231). 
A perspectiva panorâmica, obtida a partir de índices quantitativos da análise de conteúdo de 1.413 textos em 208 edições do caderno Cultura, entre 2006 e 2009, apontou tendências e valores que regem a leitura jornalística do campo cultural (AUTOR 1 et al., 2014). ${ }^{6}$ Na classificação de Traquina (2013), os valores-notícia de seleção mais frequentes foram tempo-atualidade (62,5\% das matérias), notoriedade (45\%), proximidade (21\%) e tempoefeméride $(13 \%)^{7}$. É importante ressaltar que, somados, os valores de tempo (atualidade, efeméride ou continuidade) estão presentes pelo menos uma vez em 77,3\% das matérias, refletindo condições básicas da narrativa jornalística, a pontuação e a organização do tempo da cultura.

0 acontecimento repetitivo e pré-agendado estrutura a maioria das pautas, significando o recorrente (o evento) com a visada da novidade e da diferença. A efeméride, por sua vez, presentifica o passado em ritmo cíclico e constrói a memória no espaço jornalístico efêmero. Se cruzarmos esses dois tipos de temporalidade (evento e efeméride) com os ganchos de cada um dos textos, mais da metade do total (60\%) carrega pelo menos um desses dois motes. ${ }^{8}$

Detendo-se especificamente nos dados do valor-notícia tempo-efeméride, os seis principais temas vinculados a essa rubrica são: História (em 32\% das matérias), Literatura (em 31\%), Intelectuais (em 28\%), Livros (em 19\%), Biografias (em 17\%) e Música (em 13\%), ${ }^{9}$ evidenciando novamente o quanto o suplemento aqui analisado rege-se pelos movimentos do mercado editorial e pelo interesse em repercutir pautas de viés histórico e literário. Os textos classificados pelo tempo-efeméride são, na sua maioria, reportagens (32\%), ensaios e artigos (30\%), entrevistas (12\%), críticas e resenhas (7\%), perfil (6\%), entre outros, reafirmando a prevalência dos gêneros jornalísticos como base narrativa para o tratamento desse tipo de pauta. Em 208 edições, efemérides foram capa de 52 (25\% do total de edições). Do total de textos vinculados a esta rubrica, 98 (52\%) tiveram chamada de capa.

\footnotetext{
${ }^{6} \mathrm{O}$ cadastro realizado em banco de dados criado especialmente para a pesquisa contemplou os seguintes itens: Data de Edição; Título; Chamada Principal ou Secundária; Página; Autor; Informações extras do autor; Gênero do texto; Temas; Cidade | Estado | País| Região do Tema; Valor-notícia de seleção; Frases representativas dos valores-notícia; Gancho jornalístico do texto; Cidade | Estado | País | Região do gancho jornalístico; Descrição da imagem; Comentários e Resumo do Texto.

${ }^{7}$ Cada um dos textos foi classificado, conforme o caso, em mais de um valor-notícia como categoria, já que nos interessa perceber a frequência do aparecimento desses itens ao longo do corpus selecionado.

${ }^{8}$ Os textos foram classificados pelos seguintes ganchos: lançamentos, estreias, eventos (655 matérias); efeméride (186); outros fatos jornalísticos (fora do campo da cultura) (162); morte (49); sem gancho (47); polêmica (47).

${ }^{9}$ Da mesma forma que os valores-notícia, os temas foram aferidos pela incidência nas matérias lidas.
} 


\section{As espacialidades construídas a partir das efemérides}

Após a panorâmica quantitativa da presença da efeméride no total de 208 edições, buscamos, nesse item, uma leitura qualitativa a fim de tensionar nosso objeto em torno da questão que nos mobiliza, ou seja, o quanto o jornalismo constrói narrativas sobre a cidade a partir dos seus gestos temporalizantes. Nesse intuito, reduzimos pela metade (104 edições) nossa amostra e trabalhamos com as efemérides que receberam o espaço consagrante da capa nos dois anos pares (2006 e 2008), buscando apontar tendências do conjunto. De todos os anos analisados, 2008 foi o que apresentou o maior número de datas redondas na página de maior visibilidade, 26 em um total de 52 edições (50\%). 0 ano de 2006, por sua vez, apresentou 11 pautas relacionadas aos eventos cíclicos (21\%), média próxima aos demais anos (2007 e 2009). Entre as efemérides, selecionamos aquelas que tinham ligação com a capital Porto Alegre, norte editorial de produção do caderno e que surge no mesmo como ambiente centralizador de fluxos culturais (agentes, eventos e produtos) externos e internos, uma espécie de nó em um circuito intermitente.10

Ensaiamos, a seguir, um exercício qualitativo da amostra por meio de três movimentos que, apesar de amplos, nos parecem representativos das linhas gerais do conjunto: a espacialidade personalizada; a espacialidade material; a espacialidade imaterial. A opção em usar o termo espacialidade é um desdobramento do entendimento sobre o lugar apresentado anteriormente, sempre pensado como um construto cultural, real ou imaginário. Essas escolhas resultaram tanto da frequência com que tais categorias foram localizadas no corpus, como da arbitrariedade do gesto de interpretação dos pesquisadores ao organizar, classificar e nomear índices obtidos. Vamos recorrer à análise das chamadas de capa e de fragmentos de textos a fim de exemplificar as linhas de leitura do corpus.

A primeira categoria, e mais frequente na amostra, gira em torno da espacialidade personalizada, apreendida especialmente como a personalização da cidade a partir da figura do escritor. Estudos anteriores demonstraram que a ênfase na literatura, como valor artístico e simbólico, alinha o Cultura à tradição histórica dos suplementos de jornais. Logo, o caderno projeta a cidade, personalizando-a a partir da notoriedade de quem escreve e tem um nome reconhecido na ficção literária e no mercado editorial. Os ganchos, nesse caso, são

\footnotetext{
${ }^{10}$ Estudos panorâmicos anteriores (GOLIN et al., 2014) sobre o caderno apontaram que a abrangência dos conteúdos e sua expansão para além da fronteira regional fazem do caderno Cultura um contraponto ao apelo hiperlocalista do jornal de origem. Os conteúdos ultrapassam em muito a geografia circunscrita da proximidade, mesmo que os ganchos jornalísticos - a maior parte pautado pelo evento -, acusem a força e o critério do local. Evidencia-se que é pela escolha dos colaboradores - basicamente vinculados às relações de sociabilidade da redação e às instituições regionais - que se sente o peso do olhar sobre a cultura desde o sul.
} 
os aniversários de nascimento e morte, dois balizadores típicos do enquadramento jornalístico da cultura.

O caderno Cultura, no intuito de aproximar pautas de seu local de origem, seguindo a orientação editorial de Zero Hora, tendia a valorizar os artistas e criadores locais. Entre as chamadas principais dos anos de 2006 e 2008, encontramos o valor-notícia de proximidade na rememoração de marcos biográficos de escritores que tiveram forte vínculo com a Capital. Em 2006, foi o caso do centenário de nascimento do poeta Mario Quintana, dos 10 anos da morte de Caio Fernando Abreu e dos 70 anos de vida de Luis Fernando Verissimo. Em 2008, o caderno registrou os 50 anos do cronista e professor Luís Augusto Fischer, que havia recebido o prêmio de Intelectual do Ano pela Secretaria Municipal de Cultura; os 80 anos de Sérgio da Costa Franco, escritor e historiador da cidade e os 70 anos da escritora Lya Luft. ${ }^{11}$ Em todos os textos, encontramos vestígios da relação do escritor com a cidade. São vários os vínculos: desde o fato de alguns escritores nunca terem saído da Capital; de passarem, ali, boa parte de suas vidas; de terem escolhido determinados bairros, transformando suas casas em referência personalizada de localização (por exemplo, a casa de Verissimo no bairro Petrópolis; Caio Fernando Abreu no Menino Deus; Quintana, no Centro), ou de fazerem de Porto Alegre um tema e uma personagem de suas obras.

O caso de Mario Quintana é emblemático, já que o poeta se transformou em uma espécie de estereótipo de personagem profundamente identificado com o Centro Histórico, metonímia da cidade do cartão-postal. Na série de quatro edições que apresentam o centenário do poeta na capa, não faltou o clássico desenho do traçado das ruas tantas vezes percorridas e recriadas por ele em verso, prosa e conversa fiada. ${ }^{12}$ Abaixo, destacamos dois excertos de matérias assinadas pelos jornalistas Paulo Ribeiro e Eduardo Vieira da Cunha, entreabrindo passagens para os hotéis onde Quintana morou como viajante que alterna quartos e hotéis, sempre no mesmo bairro:

\footnotetext{
${ }^{11}$ É importante situar que este tipo de pauta é recorrente em todos os anos analisados (de 2006 a 2009), especialmente no miolo do caderno. Neste artigo, estamos exemplificando aqui somente com efemérides que ganharam a capa da edição nos dois anos pares.

${ }^{12}$ Edição de 6 de maio de 2006.
} 
[...]- Olá, Seu Quintana...

- Sou!

- Poderia...

- Não!

Foi mais ou menos assim, com esta blague, que conheci Mario Quintana, em 1985. Naquele ano, o poeta mudara-se para o Hotel Royal, na Rua Marechal Floriano, no centro de Porto Alegre. 0 então Rei de Roma, Paulo Roberto Falcão, recém havia comprado o hotel e convidara o poeta para morar lá, pois Mario andava sem paradeiro (RIBEIRO, 2006, p. 2).

[...] Não me recordo da data, lembro apenas que era a terceira vez que Mario Quintana tentava. E perdia. Ele insistia tanto porque dizia que sua mãe, Virgínia, sonhara um dia que ele entraria para a Academia Brasileira de Letras. 0 poeta me recebera de pijama, com cara de insônia, e o que eu reparei só depois de revelar as fotografias é que havia uma sombra densa que se projetava naquela parede do fundo do quarto do Hotel Presidente, na Avenida Salgado Filho, bem no centro de Porto Alegre.

"Sombra minha, sombra de minha mãe", diria o poeta, reinventando legendas e brincando com a tradição de Roland Barthes (CUNHA, 2006, p. 8).

A figura do escritor é realçada, entre outros aspectos, pela sua localização na urbe, ou seja, há uma tendência em situar os escritores notórios nos endereços da cidade. Por outro lado, a imagem da sombra na fotografia projetada sobre o poeta, descrita no fragmento acima, é sugestiva para pensarmos a cidade simbólica, que cruza lugares e metáforas produzindo uma cartografia dinâmica, segundo Gomes (2008). Os percursos no mapa subjetivo da cidade, aqui articulados pela narrativa jornalística, podem surpreender pelo pretérito justaposto ao presente, pelas fantasmagorias que cercam lugares vividos, presença de ausências, como escreve Certeau (2012).

Elencamos, a seguir, um excerto do cronista e crítico Luís Augusto Fischer, que alude à imagem do aeroporto, sinalizando a entrada e a saída, fronteira e não lugar. Como pano de fundo do enquadramento das efemérides dos escritores, desponta a descrição sinestésica da cidade, o ritmo cíclico da passagem das estações, cumprindo ciclos de nascimentos e mortes:

[...] Qual não foi a sua surpresa ao ser chamado por seu nome, com um sonoro: "E aí, Caio? Voltando pra Porto?". Era Borghetinho, o rapaz nascido em Porto Alegre, que se converteu num símbolo do interior profundamente gauchesco, saudando Caio Fernando Abreu, o escritor nascido no interiorzão quase selvagem que se converteu num símbolo do que de mais urbano, cosmopolita, internacional se pode conceber na literatura. Quem estava onde, em relação a Marrakesh? Qual é a equação que conta?

Este episódio do aeroporto, Caio mencionou em uma de suas últimas crônicas, aqui mesmo na Zero Hora, e foi captado no ar outro escritor que também faleceu há 10 anos. Luiz Sérgio Metz, que era mais conhecido como Sérgio Jacaré. Exatamente 10 anos atrás, no verão de 1996, a poucos dias da morte de Caio, estive com o Jacaré em Santa Cruz do Sul, na Unisc, a convite da professora e escritora Lélia Almeida. [...] 
Por um desses golpes do destino, calhou que uma pergunta para o Jacaré versasse sobre a natureza do regionalismo, as limitações disso por aí. E ele respondeu contando a história do aeroporto, envolvendo Caio e Borghetinho, o regional e o não regional, realçando os paradoxos e optando por uma saída que mostrava que não eram tão claros assim os limites entre as coisas, quando se trata de grande arte. No inverno de 1996, morreu Luiz Sérgio Metz, poucos meses depois de Caio, que desapareceu no verão calorento de Porto Alegre (FISCHER, 2006, p. 5).

Este excerto, entrelaçando memória, escrita e cidade, lembra não apenas Gagnebin (2009; 2014), citada anteriormente, como também o clássico estudo sobre a história da cidade de Mumford (1998, p. 13). Para o autor, a origem da cidade se encontra no respeito do homem, mesmo o de Neandertal, pelos seus mortos, reservando para eles algum marco fixo em forma de pedras ou túmulo, marcos para os quais é sempre possível voltar. "A cidade dos mortos antecede a cidade dos vivos", afirma.

Assim como personaliza o lugar por meio de balizas biográficas (morte e nascimento) do escritor, o suplemento jornalístico investe na espacialidade material da cidade, outra categoria de leitura desta amostra. Nos casos analisados, verificamos a reiteração do valor mnêmico de monumentos ou prédios históricos, revisitando lugares já transformados em cartões-postais, entendidos como emblemas daquilo que deve ser dito, conhecido ou relembrado da Capital. Lembramos das constatações de Pio (2005) ao observar que os cadernos culturais estabelecem uma espécie de pedagogia da cidade, criando ou reforçando determinadas representações, muitas vezes as mesmas institucionalizadas pelas narrativas oficiais.

Nesta amostra parcial que estuda as páginas de abertura nos anos de 2006 e 2008, observamos dois exemplos desta categoria. Um deles é a visibilidade concedida pelo caderno à escultura $O$ Laçador, inaugurada em 20 de setembro de 1958 numa das entradas de Porto Alegre, aludindo à imagem do gaúcho feita a partir de um molde em gesso do pesquisador e folclorista Paixão Côrtes. No ano do cinquentenário desse monumento, Cultura escreveu: "O feriado de 20 de setembro volta os olhares de milhares de gaúchos para $O$ Laçador, a célebre escultura de Antonio Caringi cravada meio século atrás na capital do Estado. Nesta edição, Cultura discute por que essa obra se entranhou com tanta força no imaginário local". A edição tratou de discutir, junto a articulistas e fontes especializadas, a evolução da figura do gaúcho, seus aspectos históricos e sua inserção em uma tradição inventada. Na página central, a reportagem retomou a origem da peça, concebida a partir de um concurso público (1954) cujo intuito era representar o Rio Grande do Sul na Feira Internacional do 4oㅡ Centenário de São Paulo. 
Outro exemplo foi o destaque que o Theatro São Pedro ganhou no ano (2008) de seu sesquicentenário. Algo raro quando se trata de efemérides, pois foram duas capas do suplemento, sendo uma edição exclusiva sobre o tema, além de matérias esparsas em outros números. ${ }^{13}$ Como na alusão ao aeroporto destacada acima, o texto de autoria do historiador Gunter Axt retoma a ideia da fronteira, superpondo a dimensão metafórica de "janela para o mundo" no enaltecimento do edifício histórico do teatro. Vejamos alguns fragmentos:

[...] O São Pedro foi a janela de Porto Alegre para o mundo. Em 1928, por exemplo, ouviu-se o virtuose Arthur Rubinstein. De casaca, foi direto do porto para o palco, pois o navio atracara às $20 \mathrm{~h} 30 \mathrm{~min}$ e dois recitais anteriores já haviam sido cancelados devido ao atraso. [...]

Quando se interditou o São Pedro, em 1973, o teatro perdia importância social e disputava espaço com a televisão, o cinema e novas diversões.

[...] para renascer, mais glorioso do que nunca, depois de muita luta, totalmente restaurado, em 1984. Porto Alegre pôde então se reencontrar com sua janela para o mundo e com a memória de suas pujantes tradições artísticas. Rara unanimidade nacional, o São Pedro é hoje um templo. Um modelo de gestão ao qual o exigente público de Porto Alegre se refere com orgulho e com carinho: o nosso Theatro (AXT, 2008, p. 8).

A casa centenária de espetáculos, edificada na colina por onde passam as três primeiras ruas de Porto Alegre, rege-se, sobretudo, pela imaterialidade do evento. Abre-se aqui a espacialidade imaterial da cidade, terceira categoria de leitura, cuja amplitude abarca o ambiente de troca e atualização e que tem na perspectiva da fronteira um de seus emblemas. Já foi visto que a cobertura especializada em cultura enaltece, historicamente, a feição da cidade de eventos, cujo ritmo de oferta e circulação é intermitente, ponto de intersecção entre circuitos de produção artística e cultural. Na passagem dos 15 anos do Porto Alegre Em Cena, festival anual de teatro e dança que ocorre em setembro, o suplemento faz um balanço a partir do impacto provocado nas rotinas do teatro local e na projeção internacional da Capital:

0 maior defensor do festival - não poderia ser diferente - é o diretor Luciano Alabarse, coordenador do evento em 13 de suas edições. Alabarse apresenta o Paraíso à beira do lago Guaíba: o festival amplia e qualifica público, o festival qualifica e estimula os artistas locais. Alguns artistas gaúchos enxergam um enredo diferente: para eles, o Em Cena não transfere público para a cena local e se encarrega de riscar do mapa os últimos meses do ano para as temporadas locais, vitimadas pelo que seria uma over-

\footnotetext{
${ }^{13}$ Durante os anos de 2006 e 2008, um mesmo tema ganhou mais de uma capa nos seguintes casos: 100 anos do nascimento de Mario Quintana (4 capas), 150 anos do Theatro São Pedro (2), 10 anos da morte e acervo de Caio Fernando Abreu (2), 40 anos de Maio de 1968 (2), aniversário da Revolução Farroupilha (2).
} 
dose de teatro do público. [...] 0 inegável é que o Em Cena colocou Porto Alegre no mapa teatral internacional (MENDONÇAa, 2008, p. 4).

O evento evanescente e cíclico, pontuado pela cobertura, escreve uma espacialidade imaterial da cidade atravessada pelas "conexões" e pela "cultura". Enquadrada sob esta moldura, Porto Alegre é desenhada como polo catalisador de um movimento incessante de fluxos culturais. Percebemos, portanto, a positividade de um lugar que, pela força dos eventos, conecta o local ao repertório forâneo.

Determinadas chamadas de capa também direcionam o olhar para uma cidade festejada como ambiência e concentração de certos segmentos peritos. A efeméride dos 150 anos de nascimento de Sigmund Freud exemplifica este movimento de simbolização: “[...] Quase uma aldeia quando a ciência ainda engatinhava na Europa, em fins do século 19 e início do 20, a capital gaúcha é hoje um centro de referência internacional para algumas das principais correntes psicanalíticas". Percorrendo a edição de 29 de abril de 2006, encontramos, na visão da reportagem e dos especialistas ali reunidos, alguns dos motivos que levaram à consolidação deste lugar de prestígio: a ação de alguns médicos pioneiros; a reunião de diversas correntes, associações e centros de disseminação e ensino; o intercâmbio científico sistemático; a condição geográfica de fronteira, próxima a uma metrópole de referência internacional na área, Buenos Aires.

Não é de se estranhar que Porto Alegre - uma cidade de fronteira na perspectiva do imenso Brasil - tenha se transformado num centro de psicanálise a nível nacional e internacional. No fim das contas, lugares de fronteira, como acabamos de argumentar, são lugares propícios para a psicanálise. As fronteiras, como bem sabemos, não precisam ser físicas. Elas se constituem em geografias diversas, por obra do encontro de culturas, de línguas, de tradições diferentes que, no seu confronto, colocam em questão aquilo que no interior de cada povo se considerava - não havendo outras com quem comparar - verdades definitivas e absolutas (JERUSALINSKY, 2006, p. 7).

A saliência da imagem da fronteira nos aproxima novamente de Certeau (2012, p. 197), quando este afirma que "[...] tudo ocorre como se a própria delimitação fosse a ponte que abre o dentro para seu outro." Nos dois exemplos evocados, a condição tanto geográfica como simbólica de fronteira é demarcada na possibilidade de troca e intercâmbio, no movimento de entrada e saída tão recorrente nas narrativas jornalísticas sobre a cultura. Reiterase, ainda, o valor da internacionalização.

A espacialidade imaterial construída sobre a cidade também pôde ser vista na marcação de datas históricas emblemáticas, entre elas, a circularidade de 1968, descrita pelo re- 
pórter Carlos André Moreira como uma espécie de "esfinge", que "[...] retorna a cada um de seus aniversários tão rodeada de elementos e significados que nunca uma interpretação única é possível". Pelo gesto interpretativo do hiperlocalismo, os quarenta anos de 1968 foram enquadrados a partir da rebeldia vivida nas ruas e nos teatros da Capital em protesto contra a então ditadura civil-militar. A reportagem abaixo, por exemplo, buscou iluminar uma das mais expressivas passeatas estudantis daquele ano por quem as viveu. Reconstruída para responder às solicitações do tempo presente, que direciona tanto a lembrança como a narrativa jornalística, a reportagem destaca a geografia da caminhada, superpõe a subjetividade das histórias vividas no mapa objetivo das ruas:

Era muita gente. Uma multidão aglomerada no fim daquela tarde de 28 de junho de 1968, uma sexta-feira, no centro de Porto Alegre. Um grupo ruidoso, que havia saído da Reitoria da UFRGS, na Avenida Osvaldo Aranha e percorrido Sarmento Leite, Independência, Andradas, Borges de Medeiros, ganhando adesões no caminho, mais gente se agregando à passagem da multidão. Quando a passeata estacionou no Largo da Prefeitura para pronunciamentos e discursos - tinha gente empoleirada até nas bordas da Fonte Talavera de Reina - os manifestantes já serpenteavam Borges acima e só diminuíam em número à frente do Cine Vitória, à época ainda "um cinema de calçada. (MOREIRA, 2008, p. 4).

A ênfase na precisão geográfica, salientando os nomes das ruas e das regiões na cidade, produz um efeito hiper-realista sobe a memória e ativa a proximidade do leitor, tendo a cidade como pano de fundo e, por que não, protagonista pela sua expressiva espacialidade. Em linha semelhante, outra edição do Cultura, dedicada ao mesmo contexto histórico dos quarenta anos de 1968, retoma o episódio de censura ao musical Roda Vida, cuja turnê nacional resumiu-se a uma apresentação em Porto Alegre. A abertura da reportagem investe na localização espacial:

Na noite de 3 de outubro de 1968, o teatro virou caso de polícia em Porto Alegre. Logo depois de estrear no palco do Teatro Leopoldina, parte do elenco do musical Roda Viva foi agredido por radicais de direita ao chegar ao Hotel Rishon, no centro da Capital, sob gritos de "comunista", "veado" e "subversivo". Houve vários feridos. Horas mais tarde, um casal de atores de Roda Viva foi sequestrado por um grupo de agressores, levado até o Parque Saint-Hilaire, Zona Leste da Capital, e libertado depois de várias intimidações e ameaças de morte.

Na manhã seguinte, a peça de Chico Buarque de Hollanda encenada por Zé Celso Martinez seria censurada em todo o país, enquanto o elenco deixava Porto Alegre às pressas lotando um ônibus escoltado pela polícia (MENDONÇAb, 2008, p. 2).

Da mesma forma que a positividade produzida sobre o intercâmbio de fronteira, de entrada e saída dos eventos, o contexto macropolítico conflitivo que atravessa o cotidiano 
da urbe projeta uma espacialidade etérea e fragmentada sobre a cidade. Uma espacialidade tecida pelo gesto jornalístico que organiza e escolhe o que merece ser lembrado. Ao trabalhar sistematicamente com o agendamento da lembrança, o caderno ativa os vínculos de pertencimento, a singularização de espaços e participa da construção de matrizes que sustentam a memória social.

\section{Considerações finais}

Para compreender uma cidade, ensina Canevacci (1997), é preciso colher fragmentos narrados por um coro polifônico, cuja escala subjetiva nunca coincidirá com seu território. Neste âmbito, o suplemento semanal configura a possibilidade de construção seletiva da memória, agenciando a identificação e o pertencimento a um lugar investido de cultura. Ao afirmar-se como lócus supostamente perito para proceder a hierarquização dos temas mais importantes, o suplemento participa da memorabilia ${ }^{14}$ da cidade. Com seu poder de visibilidade e de escolher os motivos de presentificar o passado, ele sanciona publicamente discursos da e sobre a urbe, acionando determinadas estratégias de lembrança em que a homenagem é um recurso recorrente.

O caderno Cultura de Zero Hora recorreu de forma regular às efemérides, projetando espacialidades peculiares sobre a cidade. No ensaio exploratório realizado a partir das capas de 2006 e 2008, percebemos que o caderno personalizou o lugar e os endereços por meio da vida e da morte de seus escritores; reiterou determinados índices materiais que singularizam a capital e que são os mesmos já institucionalizados em narrativas oficiais; enfatizou a positividade e o suposto consenso de um ambiente atravessado pelo evento, pelo intercâmbio e pela capacidade de concentrar segmentos peritos, justamente a principal fonte e interlocutor do suplemento. A rememoração de datas históricas emblemáticas projetou sobre a cidade histórias vividas, invisíveis na geografia das ruas, reinventadas a cada narração tecida a partir das questões propostas pelo presente. Assentado em valores caros ao campo jornalístico, girando no entorno do calendário macro-histórico e da vida e morte de notórios, o suplemento presentifica o tempo da cultura e reescreve o texto da cidade.

\footnotetext{
${ }^{14}$ Seguimos a definição de Carlos Ceia, no E-Dicionário de Termos Literários, que define este termo latino pela amplitude de sentidos. Significa literalmente "coisas que servem para serem lembradas" e entra na literatura a partir do momento em que se torna necessário recordar, recolher ou editar obras de autores antigos por via da memória. De aplicação variada, pode-se chamar de memorabilia a tudo aquilo que teve um significado importante para um sujeito: recolha de memórias, experiências pessoais, obras realizadas, conhecimentos adquiridos, tudo que de alguma forma o marcou. Disponível em: <http://www.edtl.com.pt/index.php?option=com_mtree\&link_id=876:memorabilia\&task=viewlink>. Acesso em: 16 jul. 2015.
} 


\section{Agradecimentos}

As autoras agradecem ao Conselho Nacional de Desenvolvimento Científico e Tecnológico (CNPq) pela bolsa de produtividade concedida a Cida Golin.

\section{Referências}

ANTELO, Raul. As revistas literárias brasileiras. Boletim de Pesquisa NELIC, Florianópolis, v. 1, n. 2. Disponível em: <https://periodicos.ufsc.br/index.php/nelic/article/view/1041>. Acesso em: 11 jun. 2015.

AXT, Gunter. Janela da capital. Zero Hora, Porto Alegre, 6 dez. 2008. Caderno Cultura, p. 8.

DIAS, Andre Bonsanto. 0 presente da memória: usos do passado e as (re)construções de identidade da Folha de São Paulo, entre o "golpe de 1964" e a "ditabranda". Jundiaí: Paco Editorial, 2014.

CANEVACCI, Massimo. A cidade polifônica. 2. ed. São Paulo: Studio Nobel, 1997.

CERTEAU, Michel de. A invenção do cotidiano: artes de fazer. Petrópolis: Vozes, 2012.

CUNHA, Eduardo Vieira da. As sombras do poeta. Zero Hora, Porto Alegre, 6 maio 2006. Caderno Cultura, p. 8.

FISCHER, Luís Augusto. Pra lá de Marrakesh. Zero Hora, Porto Alegre, 11 fev. 2006. Caderno Cultura, p. 5.

FRANCISCATO, Carlos Eduardo. A fabricação do presente: como o jornalismo reformulou a experiência do tempo nas sociedades ocidentais. São Cristóvão: Editora UFS; Aracaju: Fundação Oviêdo Teixeira, 2005.

GAGNEBIN, Jeanne Marie. Escrita, morte, transmissão. In: GAGNEBIN, Jeanne Marie. Limiar, aura e rememoração: ensaios sobre Walter Benjamin. São Paulo: Editora 34, 2014.

GAGNEBIN, Jeanne Marie. Verdade e memória do passado. In: Lembrar escrever esquecer. São Paulo: Editora 34, 2009.

GOLIN, Cida et al. Índice jornalístico da cultura em suplementos: panorâmica editorial do caderno Cultura de Zero Hora (2006-2009). ENCONTRO NACIONAL DE PESQUISADORES EM JORNALISMO, 12., 2014. Santa Cruz do Sul. Santa Cruz do Sul, 2014.

GOMES, Renato Cordeiro. Todas as cidades, a cidade: literatura e experiência urbana. Rio de Janeiro: Rocco, 2008.

HALBWACHS, Maurice. A memória coletiva. São Paulo: Centauro, 2006.

HARTOG, François. Time and heritage. Museum International, Paris, v. 57, n. 3, p. 7-18, 2005.

HARVEY, David. A produção capitalista do espaço. São Paulo: Annablume, 2005. 
JEUDY, Henri-Pierre. Espelho das cidades. Rio de Janeiro: Casa da Palavra, 2005.

JERUSALINSKY, Alfredo. A descoberta de um exílio interminável. Zero Hora, Porto Alegre, 29 abr. 2006. Caderno Cultura, p. 7.

LIMONAD, Ester; RANDOLPH, Rainer. Cidade e lugar: sua representação e apropriação ideológica. R. B. Estudos Urbanos e Regionais, n. 5, p. 9-22, maio 2002.

MATHEUS, Letícia. Comunicação, tempo, história: tecendo o cotidiano em fios jornalísticos. Rio de Janeiro: Mauad X/Faperj, 2011.

MENDONÇA, Renato. A arte virou caso de polícia. Zero Hora, Porto Alegre, 11 out. 2008b. Caderno Cultura, p. 4-5.

MENDONÇA, Renato. Teatro acima de tudo. Zero Hora, Porto Alegre, 30 ago. 2008a. Caderno Cultura, p. 4-5.

MONGIN, Olivier. A condição urbana: a cidade na era da globalização. São Paulo: Estação Liberdade, 2009.

MOREIRA, Carlos André. Capital amordaçada. Zero Hora, Porto Alegre, 17 maio 2008. Caderno Cultura, p. 4-5.

MUMFORD, Lewis. A cidade na história: suas origens, transformações e perspectivas. São Paulo: Martins Fontes, 1998.

NORA, Pierre. Entre memória e história: a problemática dos lugares. Projeto História, São Paulo, n. 10, p. 7-28, dez. 1993.

PIO, Leopoldo Guilherme. Jornalismo e musealização: memória e cidade nos cadernos de cultura. Contemporânea, Rio de Janeiro, n. 5, p. 83-92, 2005.

POLLAK, Michel. Memória, esquecimento, silêncio. Estudos Históricos, Rio de Janeiro, v. 2, n. 3, p. 3-15, 1989.

RIBEIRO, Paulo. 0 eterno momento. Zero Hora, Porto Alegre, 6 maio 2006. Caderno Cultura, p. 2.

TRAQUINA, Nelson. Teorias do jornalismo: a tribo jornalística - uma comunidade interpretativa transnacional. Florianópolis: Insular, 2013.

VOGEL, Daisi. 0 caso de Senhor com a literatura: notas sobre a revista e o acontecimento. In: SOUZA LEAL, Bruno; ANTUNES, Elton; VAZ, Paulo Bernardo (Org.). Jornalismo e acontecimento: percursos metodológicos. Florianópolis: Insular, 2011. v. 2. 
The projection of the city on anniversaries in journalism: a study of Zero Hora's supplement Cultura (2006-2009)

\begin{abstract}
An anniversary indicates the power of the journalistic field to build social memory, participating on the disputes that define what must be reminded and the ways to operate this remembrance. On the planed routines of cultural journalism, anniversaries are resources to update and reinsert themes, characters and products in the economy of what is being offered in terms of cultural goods. This paper discusses how Zero Hora's supplement Cultura, between 2006 and 2009, used anniversaries and how the selection of a great part of the cyclical events has been structured as a narrative of what must be reminded about the city. It is based on obtained data from the content analysis of 1.413 texts in 208 editions. From this total, a series of cover themes were selected and analyzed for discussion. The presentification of the past indicates three movements of the city projection: the personalized spatialization, the material spatiality and the immaterial spatiality.
\end{abstract}

\title{
Keywords
}

Anniversary. Cultural supplement. Cultura (ZH). City.

Recebido em 14/09/2015

Aceito em 26/11/2015 